\title{
A DIAGNOSTIC EXPERT SYSTEM TO OVERCOME CONSTRUCTION PROBLEMS IN RIGID HIGHWAY PAVEMENT
}

\author{
Ahmed Mancy MOSA ${ }^{\mathrm{a}}$, Mohd Raihan TAHA ${ }^{\mathrm{b}}$, Amiruddin ISMAIL ${ }^{\mathrm{a}}$, Riza Atiq O. K. RAHMAT ${ }^{\mathrm{b}}$ \\ ${ }^{a}$ Sustainable Urban Transport Research Centre (SUTRA), Faculty of Engineering and Built Environment, \\ Kebangsaan University, 43600 UKM Bangi, Selangor Darul Ehsan, Malaysia \\ ${ }^{b}$ Civil and Structural Department, Faculty of Engineering and Built Environment, Kebangsaan University, \\ 43600 UKM Bangi, Selangor Darul Ehsan, Malaysia
}

Received 16 Jan 2012; accepted 2 May 2012

\begin{abstract}
Constructing highway pavements faces complex problems, which are affected by multiple factors, where solution is nearly impossible without expert assistance. Diagnosing such construction problems and suggesting most suitable cost efficient solutions requires significant engineering expertise, which might not be available in all construction sites due to inadequate resource and remote locations. Developing an expert system in this domain is a very effective way to help novice engineers to overcome these problems and to learn about them. Moreover, the system can be used as an archive to document engineering knowledge and to share expertise among the experts in this domain. This article describes the development and evaluation stages of such a system, including knowledge acquisition, knowledge representation, system building, and system verification and validation. The initial knowledge is acquired from literature reviews. More expert knowledge is elicited through interviews and questionnaires. This knowledge is documented, analyzed, represented, and converted to computer software using the Visual Basic programming language and the system is called ES-CCPRHP. The system has been verified and validated in three ways: by extensive testing, comparison between system performance and expert reasoning, and case study. It can therefore be employed with confidence by end users.
\end{abstract}

Keywords: expert system; construction problems; rigid highway pavements; solutions; causes.

Reference to this paper should be made as follows: Mosa, A. M.; Taha, M. R.; Ismail, A.; Rahmat, R. A. O. K. 2013. A diagnostic expert system to overcome construction problems in rigid highway pavement, Journal of Civil Engineering and Management 19(6): 846-861. http://dx.doi.org/10.3846/13923730.2013.801905

\section{Introduction}

Rapid urbanization and increase in population create a high demand for infrastructure to transport products, raw materials, and people faster and safer between localities (Mulungye et al. 2007; Syamsunur et al. 2011). Construction of a highway system as a part of public infrastructure is a significant way for any country to improve and boost economy (Chou, Tseng 2011; Mulungye et al. 2007; Santos et al. 2010).

During the construction of rigid pavements, highway engineers face many problems that they must decide the controlling measures. The expected problems range from mildly disruptive to financially catastrophic. Generally, these problems affect the quality of the construction and increase initial cost. Experts can control and solve these problems using their tacit knowledge (Miller et al. 2007). However, novice engineers cannot overcome such problems, suggest suitable solutions, avoid their causes, and prevent the same problems from occurring in other parts of the work. Transfer of expertise from experts to novices is difficult in the domain of construction (Persson, Landin 2007). Therefore, there is a need for a system in which experts could share their experience with other engineers both during a project and afterward. If no such transfer of expertise and knowledge occurs, the novices may repeat the mistakes that the experts have learned how to avoid (Persson, Landin 2007). Documentation, classification and computerization of these problems, their causes, solutions, and preventive actions can be very helpful for controlling and preventing them.

This paper describes the development of an expert system that can be used by novice engineers on rigid highway pavement construction sites to control the problems that they encounter. The system can also be used as an instructional tool for interested highway engineers. In addition, the system can archive and organize raw knowledge from experts for use by all engineers working in this field. Domain experts can use the system to share experiences. The proposed system is supported by a Geographic Information System (GIS) to provide location, weather, and traffic information. 
Expert systems are used to overcome problems in fields from assessment to engineering consulting (RuizMezcua et al. 2011) by employing human expertise in different domains (Qian et al. 2005). Expert systems can be used in any field (Ooshaksaraie et al. 2012). Therefore, using expert systems to solve sophisticated engineering problems that require a significant amount of experience is very common, and researchers have developed many systems for use in different fields (Park et al. 2010).

In highway construction industry, many expert systems were developed in the domain of design and maintenance and rehabilitation, but to author's knowledge, no such systems were developed for pavement construction.

In design stage, Syamsunur et al. (2011) developed an expert system for route selection that uses GIS techniques and opinions of human experts. This system could be considered as a new version of the system developed by Mohsen and Crower (1991). Teh et al. (2005) developed an expert system named RC-MMS, which supports designers in material selection for highway pavements (Teh et al. 2005). This system is similar to the system developed by Hozayen and Haas (1992). Deprizon developed an expert system to assist engineers in the structural design of flexible highway pavements. The system uses the American Association for State Highways and Transportation Officials (AASHTO) standards and human expertise acquired from domain experts to calculate the minimum thickness of the layers of flexible highway pavements (Deprizon et al. 2009). Goh (1993) developed an advisory expert system to simulate the designer procedure in design of structural layers of asphalt pavements based on the available information of materials, traffic and area conditions. Khedr and Mikhail (1996) developed an expert system named EXPAVE to provide assistance to the novice designers in flexible pavements during the design stage. EXPAVE is also capable of predicting the structural performance of the existing pavements and enable designing of the overlays (Khedr, Mikhail 1996).

In the domain of pavement management, Kaur and Tekkedil (2000) developed a fuzzy expert system, which employs the information about the materials used, thickness of the flexible pavement layers, traffic characteristics, and road age to predict the pavement performance in the form of rut depth. Kuprenas et al. (1995) developed a forward-chaining rule-based expert system to identify failure causes in flexible pavements. Tsao et al. (1994) developed a vision expert system to diagnose the distresses in rigid highway pavements without human interaction based on the images of the distresses. Lan et al. (1993) developed an expert system named PDS (Pavement Distress System) to diagnose distresses of flexible pavement based on the expertise of Taiwanese experts. Other expert systems were developed in the domain of pavement maintenance and rehabilitation management as classified by Ismail $(2009 a, b)$.

The current study presents the development stages of the ES-CCPRHP, which is an expert system that controls construction problems in rigid highway pavements. Prior to the development process, the need for such a system was determined from a literature review and validated by a questionnaire survey. The first stage involved knowledge acquisition from written sources and from domain experts via interviews and questionnaires. The acquired knowledge was classified under the supervision of domain experts, after which the classified knowledge was represented in the form of rules. The third stage involved building the system by coding the rules using Visual Basic. In the fourth stage, the system was verified and validated by unit and integrated testing, user satisfaction testing, behavior comparison between the system and experts, and case study. The developed system can be used with confidence and easily updated.

\section{Rigid pavement construction}

Construction of rigid pavements process is sophisticated, and involves many activities like concrete producing, placing, spreading, compacting, finishing, texturing, curing, protecting, jointing, testing, and other sub-activities. In addition, this process is performed over large areas, outdoors, and under miscellaneous conditions. Therefore, problems are very usual during construction (O'Flaherty 1988; Oglesby, Hicks 1982).

In fact, the same materials, which are, cement, sand, aggregate, water and reinforcement, are used to prepare the mix which is used in the construction of rigid pavements. The obtained slab sometimes behaves and looks good, and other times that same slab can exhibit bad qualities. There is no simple answer to explain these differences in the obtained products, but major contributing factors that can be summarized as follows (ACI Committee 304R-00 2000; ACI Committee 306.1-90 2002; ACI Committee 305.1-06 2007):

1) Over the years, the engineers and contractors have had to deal with major changes in methods of construction. There is ever increasing difficulty to find staff with the necessary skill and experience able to carry out concreting operations on site. Computerized design methods move the engineers even further from practical realities. It is still easier to assess and test material products than its construction practices.

2) Most of concrete today is manufactured off the job site and away from the direct control of the resident engineer (which is a ready mixed concrete). This has produced another contractual and communications interface, where misunderstandings and mistakes may occur.

3) The aspect of environmental protection and energy saving has led to greater planning restriction on cement and aggregate material processing and pressed to use by-products such as pulverized fuel ash, ground granulated slag and silica fume, often of unknown and variable quality. Again, the lack of experience, proper understanding, and control over the use of these materials can lead to problems. 
4) Adverse climatic conditions may influence the construction operation and then affect the quality desired.

5) Bad preparation and scheduling at the site can cause interruption among the construction operation stages.

The experts can manage the operation and overcome the problems faced during construction, but the novice engineers need support to do that.

Cracking is one of the major problems encountered in rigid pavements. Different types of cracks are very common in highway pavements. Crack is a complete or incomplete separation of concrete into two or more parts produced by breaking or fracturing (ACI Committee 116R-00 2000). Cracking can be classified into plastic concrete cracking and cracking of hardened concrete. Cracking of plastic concrete involves cracks occurring at the surface of fresh concrete during the interval after concrete placing (when it is possible to be re-moulded) and before concrete hardening (ACI Committee 116R-00 2000). This interval may range from 1 hour to 12 hours depending on air temperature, water content in mixture, and use of accelerators or retarders in mixture. On the other hand, cracking of hardened concrete occurs due to shrinkage of concrete. Problems involved in this pattern of cracking could be considered as a construction problem if they occur before opening the road for the traffic.
Restraint of pavement can cause cracking in two patterns that are cracks within slab and cracks near joints. Cracking includes the following types:

1) Diagonal shallow cracks;

2) Craze cracks;

3) Transverse and oblique cracks;

4) Longitudinal cracks;

5) Corner cracks (D-cracks);

6) Transverse and diagonal cracks at transverse joints;

7) Longitudinal cracks at longitudinal joints;

8) Cracks at the intersection of joints.

Table 1 abstracts the causes of the crack generation.

\section{The need for the proposed system}

Based on the literature review and the concepts explained in existing research, there is a serious need for an expert system in the domain under study. This conclusion was tested with a questionnaire survey. This is a new approach in comparison with other studies in this area. Other researchers have depended on the literature to establish the need for their proposed expert system. After developing their system, they use a questionnaire to check if it is needed. The present approach has two major advantages over the approach used by other researchers. First, ensuring that there is a real need for the proposed system before creating it will avoid wasting time, money, and effort on developing a system that is not required. Second, the

Table 1. Causes of cracking problems

\begin{tabular}{|c|c|c|c|c|c|c|c|c|}
\hline \multirow[b]{2}{*}{ Causes } & \multicolumn{8}{|c|}{ Cracking problems } \\
\hline & $\mathrm{i}$ & ii & iii & iv & $\mathrm{v}$ & vi & vii & viii \\
\hline Hot weather $\left(T>=30^{\circ} \mathrm{C}\right.$, low humidity, windy) & $\mathrm{x}$ & & & & & & & \\
\hline Insufficient or late curing & $\mathrm{x}$ & $\mathrm{x}$ & $\mathrm{x}$ & $\mathrm{x}$ & & & & \\
\hline Improper finishing by excessive floating or trowelling & & $\mathrm{x}$ & & & & & & \\
\hline Applying of cement powder on surface before finishing & & $\mathrm{x}$ & & & & & & \\
\hline $\begin{array}{l}\text { Restriction of pavement slab due to dowel bars restraint at } \\
\text { joints or due to excessive irregularities of roadbed or lack } \\
\text { of separation membrane }\end{array}$ & & & $\mathrm{x}$ & $\mathrm{x}$ & $\mathrm{x}$ & $\mathrm{x}$ & & \\
\hline High concrete shrinkage due to high water content & & & $\mathrm{x}$ & $\mathrm{x}$ & & & & \\
\hline High entrapped air content due to improper compaction & & & $\mathrm{x}$ & & & & & \\
\hline Late sawing or low depth of contraction joint grooves & & & $\mathrm{x}$ & $\mathrm{x}$ & & $\mathrm{x}$ & & \\
\hline High spaced contraction joints in unreinforced pavement & & & $\mathrm{x}$ & $\mathrm{x}$ & & & & \\
\hline Presence of an active alkali aggregate in mixture & & & $\mathrm{x}$ & & & & & \\
\hline Improper protection from harmful weather conditions & & & $\mathrm{x}$ & $\mathrm{x}$ & & & & \\
\hline Trapping of stone pieces in sealed grooves & & & & & $\mathrm{x}$ & & & \\
\hline Poorly compacted concrete around joint grooves & & & & & & $\mathrm{x}$ & & \\
\hline Discontinuity of the joint groove in the vertical direction & & & & & & $\mathrm{x}$ & & \\
\hline Misaligned top and bottom crack inducers & & & & & & & $\mathrm{x}$ & \\
\hline Omission of bottom cracks inducers & & & & & & & $\mathrm{x}$ & \\
\hline Discontinuity of the joints grooves at their intersections & & & & & & & & $\mathrm{x}$ \\
\hline Improper construction or misalignment of the joints & & & & & & & & $\mathrm{x}$ \\
\hline
\end{tabular}


domain of the study can be specified depending on the comments of questionnaire respondents.

The questionnaires were submitted to 30 highway engineers who had different levels of experience. The engineers were divided into two groups. The first group included eight engineers who had between 5 and 9 years of experience and two experts with more than 20 years of experience. The second group included 20 engineers who had 3 years of experience or less. The questionnaire consists of two parts and a total of seven questions. Of these, five questions ask about the significance of the proposed system and its role in the study domain, and the other two questions ask about the number of domain experts. Because a Likert scale is a very effective way to evaluate the results of a questionnaire (Göb et al. 2007; Lee et al. 2010), the questions are evaluated on 5-point Likert scale, where the value 1 represents "strongly disagree" and the value 5 represents "strongly agree". The results, summarized in Table 2, speak for themselves and reflect the significance for the proposed system. The results express a significant concern over the loss of human expertise as experts retire or pass away. The proposed system can preserve their expertise in a classified form and can help to educate a new generation of experts. In summary, the results of the questionnaire validate the conclusion extracted from the literature, that is, there is high demand for an expert system in the domain of highway pavement.

\section{Developing the system}

An expert system uses knowledge instead of data to solve problems. An expert system development team is led by a knowledge engineer and includes a domain expert and an end user. The role of the knowledge engineer is to build the system by acquiring knowledge from written sources and from the domain expert. During the knowledge acquisition stage, the knowledge engineer works with the domain expert to acquire, classify and analyze the knowledge. The knowledge engineer codes the acquired knowledge in a classified form to construct a computer system using a programming tool. The constructed system is tested and evaluated by the end user, who is the third member of the team (Alani et al. 2009; Raza 2009; Špundak et al. 2010). The proposed expert system in this study (ES-CCPRHP) has passed through the stages of development successfully.

Many studies have investigated the integrated usage of expert systems, which can simulate the performance of a human expert (Ahmadi, Ebadi 2010), and GIS, which has many uses in decision making (Demircan et al. 2011; Sikder 2009), in fields such as ecology, agriculture, forestry, transportation, traffic, public health, and environmental protection (Wei et al. 2011). GIS can provide information about location, weather conditions, road traffic, and other data (Durduran 2010; Niaraki, Kim 2009; Sadeghi-Niaraki et al. 2011).

\subsection{Knowledge acquisition and representation}

Knowledge acquisition represents the most important stage in the development of an expert system (Raza 2009). It is also complicated and time-consuming (Mohd. Zain et al. 2005; Ooshaksaraie et al. 2012; Tan et al. 2010) as knowledge-based systems require specific analytical approaches (Castellanos et al. 2011). Knowledge acquisition involves obtaining and classifying expertise from miscellaneous sources (Qian et al. 2008). Knowledge engineering methodology usually starts with reviewing written sources, like books, guidelines, manuals, and papers associated with the problem domain. Further knowledge can be elicited from domain experts. Then, the collected knowledge can be combined, studied, and analyzed repeatedly (Negnevitsky 2005).

In the present study, an extensive review of specialized sources is performed to construct the initial background knowledge and understand the concepts of rigid pavement construction and the problems that can be expected to occur during different stages of construction.

Table 2. Analysis of the questionnaire on the need for the proposed system

\begin{tabular}{|c|c|c|c|c|c|c|c|}
\hline \multirow[b]{2}{*}{ No. } & \multirow[b]{2}{*}{ Questions } & \multicolumn{2}{|c|}{ Group 1} & \multicolumn{2}{|c|}{ Group 2} & \multirow[b]{2}{*}{$t$} & \multirow[b]{2}{*}{$p$} \\
\hline & & Mean & SD & Mean & SD & & \\
\hline Q1 & The proposed system will be very important & 4.800 & 0.632 & 4.800 & 0.615 & 0.000 & 1.000 \\
\hline Q2 & $\begin{array}{l}\text { The proposed system will help novice } \\
\text { engineers to solve the domain problems }\end{array}$ & 4.800 & 0.632 & 4.900 & 0.447 & 0.502 & 0.619 \\
\hline Q3 & $\begin{array}{l}\text { The proposed system can help an engineer to } \\
\text { learn about the domain problems }\end{array}$ & 5.000 & 0.000 & 4.500 & 0.889 & 1.763 & 0.089 \\
\hline Q4 & $\begin{array}{l}\text { The proposed system will be used as an } \\
\text { archive to document the domain problems }\end{array}$ & 4.800 & 0.632 & 4.600 & 0.821 & 0.675 & 0.505 \\
\hline Q5 & $\begin{array}{l}\text { The proposed system can be used to } \\
\text { interchange the expertise among the } \\
\text { engineers in the domain of the study }\end{array}$ & 4.800 & 0.632 & 4.600 & 0.821 & 0.675 & 0.505 \\
\hline Q6 & $\begin{array}{l}\text { The number of domain experts is not enough } \\
\text { to cover the volume of the projects }\end{array}$ & 3.800 & 1.033 & 4.300 & 0.979 & 1.295 & 0.206 \\
\hline Q7 & The number of domain experts is decreasing & 3.000 & 1.333 & 3.800 & 1.361 & 1.528 & 0.138 \\
\hline
\end{tabular}


Through this review, the initial knowledge base is constructed as the foundation for the final knowledge base that represents the core of the expert system. This initial knowledge is analyzed repeatedly to refine it and limit the domain of the study. The review focuses on description, causes, and prevention of problems, instantaneous solutions to problems that occur, and the possible effects of problems that are not avoided or controlled. After construction of the initial knowledge base through a literature review, domain experts were consulted about their knowledge. The experts obtained their domain knowledge gradually through education and experience. Selection of domain experts is very significant in any elicitation expertise. Criteria for choosing domain experts ensure elicitation of correct expert knowledge. There are two major criteria for domain experts. The first is the length of experience in the domain, which affects the judgment and analytical behavior of the expert. The second can be represented in circumstances in which the expertise is obtained, which could be theoretical, practical, or a combination of both (Osuagwu, Okafor 2010). Depending on these criteria, a set of four experts was selected for the human expertise stage in the present study. The selected experts are well known and have broad experience in the domain of rigid pavement construction, as illustrated in Table 3. Another set of experts is selected to participate in the evaluation stage. Knowledge elicitation involves obtaining knowledge from experts to understand how they make decisions. This goal can be achieved by methods such as interviews (Tan et al. 2010). Experts can also be observed as they work to identify implicit knowledge (Castellanos et al. 2011; Tan et al. 2010). The knowledge engineer can decide on which method to use depending on the study domain, amount of knowledge needed, and the efforts required to analyze the collected information (Osuagwu, Okafor 2010). In this paper, expertise was elicited from the selected experts by unstructured interviews, structured interviews, and questionnaires. Unstructured interviews were held with the experts to gain a general understanding of their practical experience with domain problems and to build a friendly relationship with them to simplify the process of expertise elicitation. Problems in the study domain were discussed in general, and a few problems were discussed specifically. Each expert referred to some of his practical experiences with rigid pavement construction problems and the way he dealt with such problems in the field.
During the unstructured interviews, only a few questions were asked of the experts, but the experts gave detailed responses to these questions. After each unstructured interview, the knowledge was reanalyzed, reclassified, and updated in preparation for structured interviews, which represent the next step in expertise elicitation. During structured interviews, a specific aspect of the domain is emphasized in each interview to ensure robust results. The primary knowledge that is collected through expertise elicitation is much more than the secondary knowledge obtained from the literature, because the experts do not document their experiences. The acquired knowledge was abstracted in questionnaire form and submitted to the experts to complete the knowledge acquisition stage. A questionnaire can simplify the process of knowledge elicitation from experts (Ma et al. 2011) because it gives the expert time to think about his response before answering. Questionnaires are an effective way to elicit knowledge as they can save time, money, and effort, especially when the knowledge engineer knows exactly the required knowledge characteristics (Rezaei et al. 2011). In addition, the classified form of the questionnaire simplifies the mission of the expert because he can review each problem separately. Blank spaces were provided following each question for the expert to write his comments. Three experts completed questionnaires, and only one questionnaire form was not returned. One of the experts asked for clarification before answering some of the questions. The experts provided many useful comments on the questionnaire that enriched the knowledge base. After reviewing and analysis of their answers and comments in the questionnaire, the experts were interviewed again to clarify some points in their comments and to focus on some details in their solutions to the problems. In the final step of the knowledge acquisition process, the knowledge base is reanalyzed and rearranged in preparation for final classification.

Through the extensive review and repeated analysis of the acquired knowledge, the domain problems are classified depending on their forms, locations, effects, and other common features so that inspectors can diagnose a problem visually or via tests and measurement results. In addition, problems' description, likely causes, preventive actions, instantaneous solutions, and their possible effects if they are not controlled are stated. The repeated classification stages were discussed with experts for modification. The final classification was reviewed by three experts

Table 3. Experts involved in expertise elicitation

\begin{tabular}{l|c|c|c|c|c|c}
\hline $\begin{array}{l}\text { Expert } \\
\text { number }\end{array}$ & Academic degree & $\begin{array}{c}\text { Years of } \\
\text { experience }\end{array}$ & $\begin{array}{c}\text { Unstructured } \\
\text { interviews }\end{array}$ & $\begin{array}{c}\text { Structured } \\
\text { interviews }\end{array}$ & $\begin{array}{c}\text { Focus interviews } \\
\text { (after } \\
\text { questionnaire } \\
\text { completion) }\end{array}$ \\
\hline 1 & PhD & 27 & Yes & Yes & Yes & Yes \\
\hline 2 & Master & 24 & Yes & Yes & Yes & Yes \\
\hline 3 & Master & 21 & Yes & Yes & Yes & Yes \\
\hline 4 & Master & 20 & Yes & Yes & No & No \\
\hline
\end{tabular}




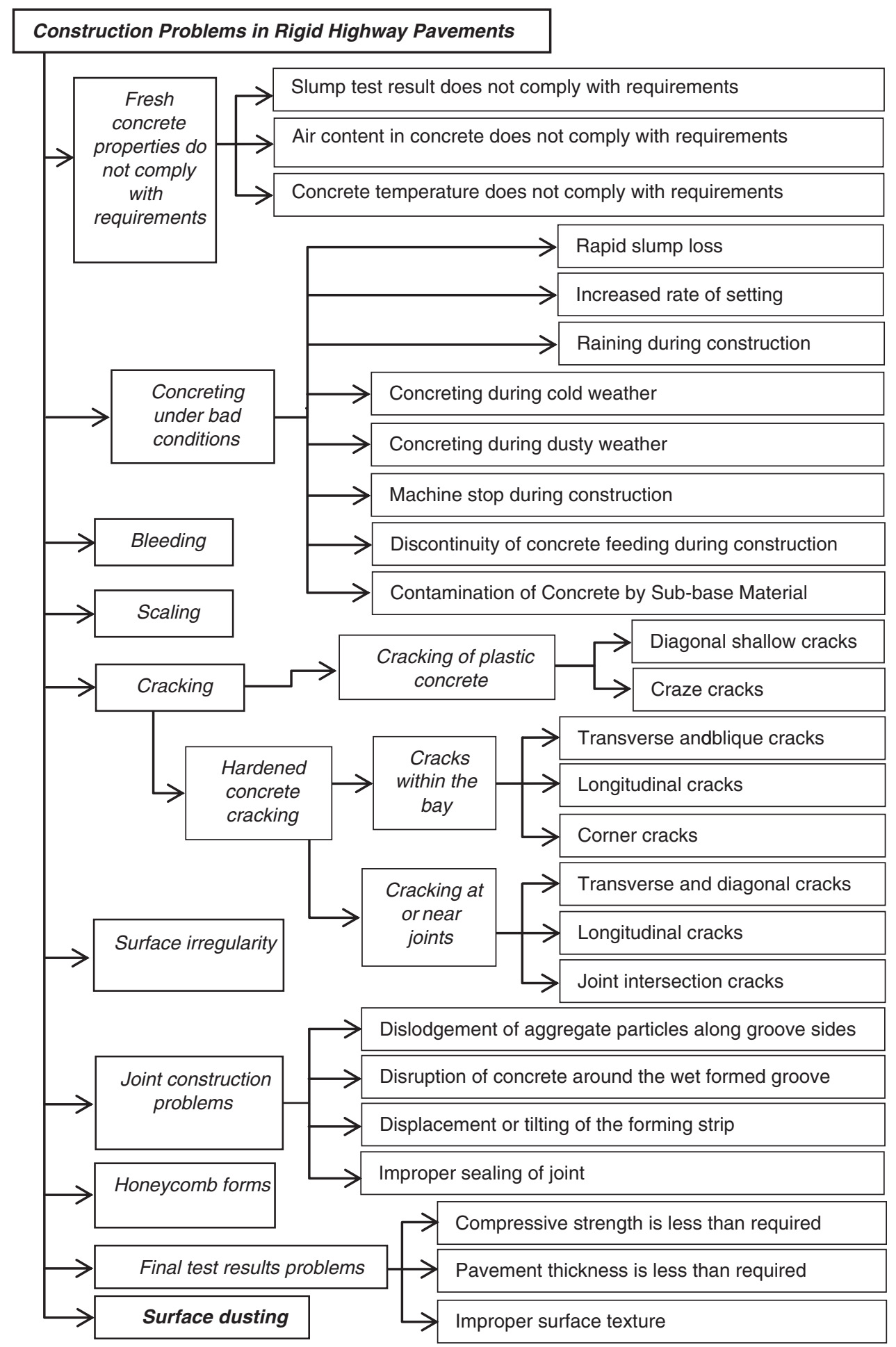

Fig. 1. Construction problems in rigid pavement

during the focus interviews, and they agreed that it represented their knowledge well. Figure 1 illustrates the classification diagram of the titles of the problems.

The problems are identified depending on their characteristics, which could be diagnosed visually by their appearance or by measurements and tests. The name of each problem summarizes its description. Experts can note such problems easily and quickly make decisions to solve them, whereas novice engineers cannot.
Avoiding these problems by preventive actions can save time, money, and effort. Immediate decisions to identify and take preventive measures must be made to control these problems. Site inspectors have the authority to reject any load that contains an imperfect concrete. The decision to reject a load can be based on visual inspection, temperature measurement, or tests. Accepted loads should be documented in detail, including their placing, temperature, sample number, slump, and other remarks. 


\subsection{Building the system}

In this study, an expert system is developed to detect problems and guide the user through the diagnostic process. Knowledge about these problems can be represented in the form of rules. Therefore, a rule-based system can be considered as the most correct option. When problems arise, experts need to collect information about it and then make a decision. Therefore, a forward-chaining inference engine, which is data driven, is suitable for knowledge representation in a rule-based expert system (Negnevitsky 2005). This procedure works from the facts in the knowledge base toward the goal or conclusion (Chu et al. 2009; Špundak et al. 2010). The reasoning originates from the given information, and then continues forward with that information. This approach depends on IF-THEN relationships; if the IF condition is matched in a rule, the action in its THEN part is applied (Negnevitsky 2005). This process can be modelled as IF (condition) THEN (conclusion) (Cebi et al. 2009; Přibyl 2010). We created 450 ES-CCPRHP rules, which simulate the manner in which domain experts think.

The classified knowledge, which represents the core of the proposed system, is prepared in the form of rules to be coded in a computer environment. The Microsoft Visual Basic programming language was used to develop ES-CCPRHP, because this language is a very effective and flexible tool for software development in the Windows environment. In addition, Microsoft Visual Basic is suitable for use with GIS (Ooshaksaraie et al. 2012). The source code version of the developed system has multiple forms that are connected together in one structure. Each form includes a number of commands responsible for executing specific functions in the system. The forms and the commands are given clear, expressive names that are related to the functions of each command. In addition, many remarks are included in the coding menus to simplify the updating process. This version (with the extension.vbp) is designed for use by the knowledge engineer who is responsible for developing and updating the system. An executable version (with the extension. exe) is prepared for use by the end user, who is the highway engineer, and this version is protected and cannot be edited. Figure 2 illustrates the relationships among the development team and components of ES-CCPRHP. The system can be operated easily by clicking a button to execute any step using the mouse or the keyboard; the

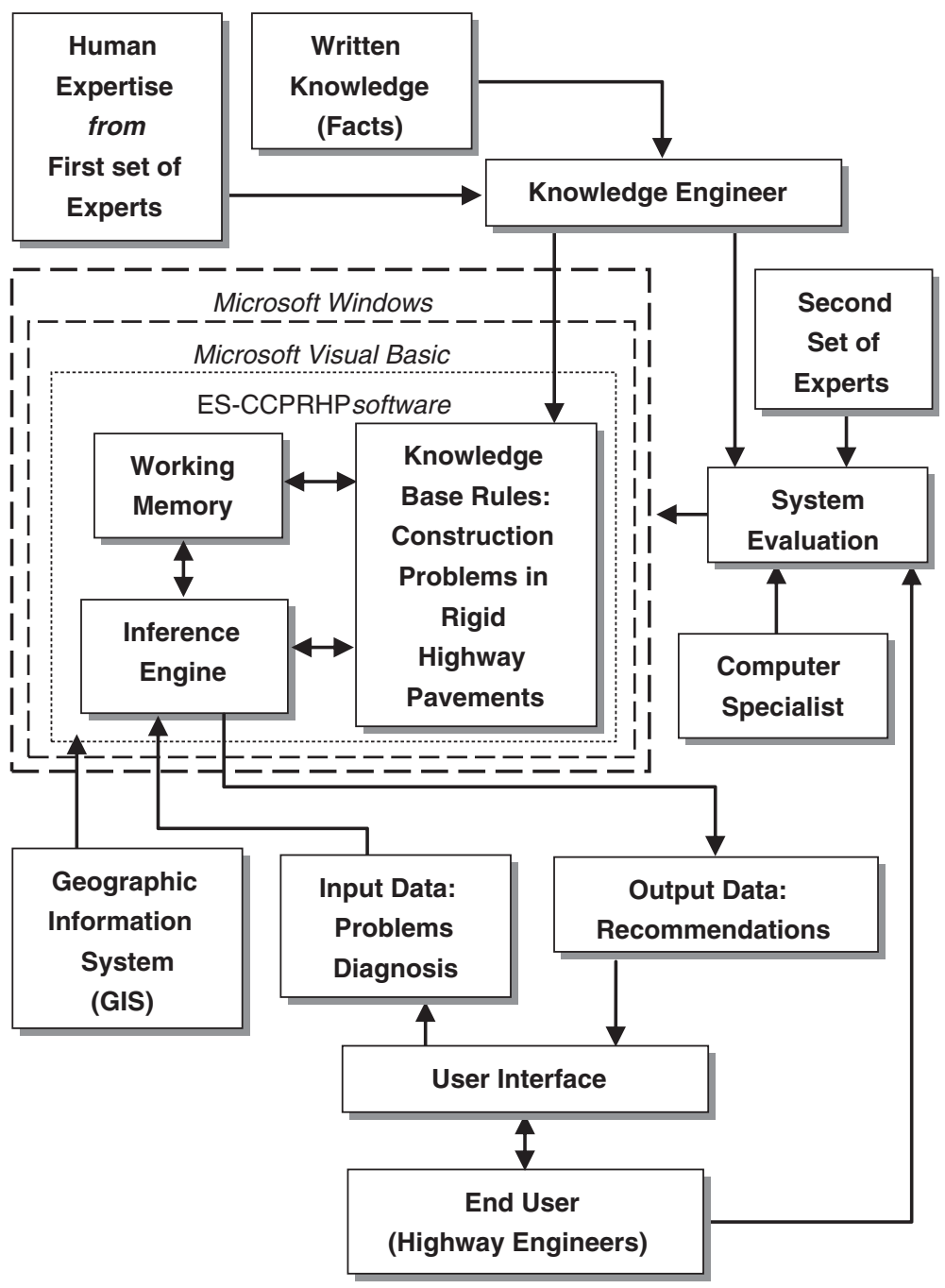

Fig. 2. Relationships among development team and ES-CCPRHP structure 
user can return to the last step anytime using a Back button, and he can use the Close button to end the program at any stage. The system is coded in a simple manner to ensure easy updating by the developer or any other knowledge engineer in this domain, who is familiar with Visual Basic language.

\subsection{System operation}

Similar to any software in the environment of Microsoft Windows, the system can be run by clicking the icon of the executable file or its shortcut. The system runs immediately and displays a greeting screen that includes information about the purpose of the system, the domain that the system deals with, a brief guide about operating the system, and three command buttons (CONTINUE, ABOUT, and CLOSE). Users can press any button using the mouse or keyboard, and then proceed to the next screen by pressing the CONTINUE button. The next screen presents the flow chart of domain problems to provide the novices in this domain with an idea about the problems. This screen also describes the construction stages, as well as the probable problems and their probable causes as part of the training process, providing novices a background for moving on to the next screen. Users can skip this screen by pressing CONTINUE if they already have sufficient background knowledge or if they are in a hurry to find solutions. Such a situation usually occurs in problems encountered during paving operations, including defective concrete loads, bleeding or cracking of fresh concrete, and paving stoppage due to bad weather conditions or equipment breakdown. The next screen includes all the problems that are classified into main and subcategories of common features. The titles of the categories, subcategories, and problems simplify descriptions for users. For example, the cracking category includes two subcategories (cracking of plastic concrete and cracking of hardened concrete). Cracking of plastic concrete includes diagonal shallow cracks and craze cracks. The titles clearly reflect the properties of a problem for simplified diagnosis. Figure 3 presents the cracking subcategories and specific problems in one input screen. In addition, the descriptions of each category, subcategory, and problem can be displayed on separate screens by pressing the related button. Moreover, pictures that clarify the problem can be displayed. Videos of test procedures are also provided, which can be activated with the press of a button. Users can select a category of problems or one problem or more by selecting an option button or checking TICK on checkboxes. The system asks a user if the description presented complies with the description of the problem in the worksite. When a user confirms by selecting the YES button or checking TICK on the checkboxes, the system proceeds with the diagnostic process by asking for more input data, such as test results, field measurements, work requirements that are documented in project files (e.g. designed pavement thickness, designed concrete strength, and specified minimum and maximum values of the tests). The system uses default values when a user does not answer questions by providing the user multiple options. For example, when a structural problem occurs in constructed pavement (thickness and/or strength deficiency), the inference engine will run a redesign subroutine to evaluate the pavement's structural properties on the basis of existing input. The system will ask the user to incorporate some values as explained in Section 3.4.4. One of the required values in this case is the load transfer coefficient. If a user does not know this value, the system presents multiple options for the type of load transfer to help the user select the

\begin{tabular}{|c|c|c|c|c|}
\hline Q ES-CCPRHP & & & Cracking & 마밀 \\
\hline \multirow{3}{*}{$\begin{array}{l}\text { ES-CCPRHP } \\
\text { put Screen for: Cracking }\end{array}$} & $\sqrt{\text { ware. }}$ & Help & Properties & $\begin{array}{l}\text { Results and } \\
\text { Recommendations }\end{array}$ \\
\hline & \multirow{2}{*}{$\cos ^{2} x^{2}$} & Back & \multirow{2}{*}{$\begin{array}{l}\text { Slump Test } \\
\text { Enter the value of slump } \quad \square \mathrm{mm} \\
\text { More Details } \quad \text { Video }\end{array}$} & Instantaneous Solution \\
\hline & & \multirow[t]{2}{*}{ Close } & & Causes \\
\hline \multirow{3}{*}{\multicolumn{3}{|c|}{$\begin{array}{l}\text { Cracking Problems - Deseription } \\
\text { Cracking of plastic concrete - Deseription }\end{array}$}} & \multirow{2}{*}{$\begin{array}{l}\text { Concrete temperature } \\
\text { Enter concrete temperature } \quad \square \text { oC }\end{array}$} & Expected Effects \\
\hline & & & & Preventive Actions \\
\hline & & & More Details Video & All Results \\
\hline \multirow{3}{*}{$\begin{array}{l}\text { Diagonal shallow cracks } \\
\text { - Craze cracks }\end{array}$} & Deseription & Pictures & \multirow{3}{*}{$\begin{array}{l}\text { General Specificactions } \\
\text { Cement content }(\mathrm{kg} / \mathrm{m} 3) \quad \text { W/C } \\
\text { Selected the used additives if any }\end{array}$} & \multirow{4}{*}{$\begin{array}{l}\text { Plant and Hauling Type } \\
\text { Truck Type } \\
\text { Truck Mixer } \\
\text { Type of Concrete Plant } \\
\text { Batch Plant }\end{array}$} \\
\hline & \multirow{2}{*}{ Description } & \multirow{2}{*}{ Pictures } & & \\
\hline & & & & \\
\hline \multicolumn{3}{|c|}{ Cracking of hardened concrete Deseription } & $\begin{array}{ll}\ulcorner\text { Super plasticizer } & \ulcorner\text { Retarder } \\
\ulcorner\text { Hardener } & \ulcorner\text { Others additives }\end{array}$ & \\
\hline \multicolumn{3}{|l|}{ Cracks within the bay - Deseription } & Spacing between transverse joints $\square$ m & Tests and Requirments \\
\hline \multicolumn{2}{|c|}{ c Transverse and oblique cracks Description } & Pietures & \multirow{2}{*}{ 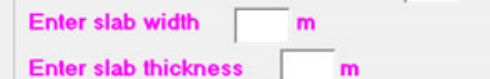 } & Job mix formula Screen \\
\hline \multirow{2}{*}{$\begin{array}{l}\sim \text { Longitudinal cracks } \\
\sim \text { Corner cracks }\end{array}$} & Description & Pietures & & Main Screen \\
\hline & Deseription & Pietures & \multirow{2}{*}{$\begin{array}{l}\text { Enter slab thickness } \quad \text { m } \\
\text { Reinforcement } \\
\text { - Reinforced } \quad \text { Unreinforced (Plain) }\end{array}$} & Standard Specifications \\
\hline \multirow{2}{*}{\multicolumn{3}{|c|}{ Cracking crack at or near joints - Deseription }} & & Laboratory Tests \\
\hline & & & \multicolumn{2}{|l|}{ Alkali Aggregates Used in Concrete } \\
\hline \multirow{2}{*}{$\begin{array}{l}\curvearrowright \text { Transverse and diagonal cracks } \\
\curvearrowright \text { Longitudinal cracks }\end{array}$} & Description & Pietures & $\ulcorner$ Yes $\subset$ I do not know $\subset$ No & Field Measurements \\
\hline & Deseription & Pietures & Overall Plastic Concrete Proderties & Important Remarks \\
\hline \multirow{2}{*}{$\checkmark$ Joint intersection cracks } & & & - Homogenous $\subset$ Not homogenous $\sim$ Segregated & Miscellaneous \\
\hline & Description & Pietures & $\sim$ Coarse (Harsh) $\sim$ Regular & Help \\
\hline
\end{tabular}

Fig. 3. ES-CCPRHP cracking input screen 
correct option. In this example, the options are undoweled pavement on crushed aggregate surfacing, doweled pavement on crushed aggregate surfacing, doweled pavement on hot mix asphalt (without a widened outside lane) and tied pavement shoulders, continuously reinforced pavement with hot mix asphalt shoulders, and continuously reinforced concrete pavement with tied concrete shoulders. When the user selects an option, the system uses the related default value stored in the working memory.

The inference engine manipulates the input data and facts in the working memory in a reasoning process in the knowledge base to match these data with related rules, draw a conclusion, and display recommendations. More details can be found in the examples provided in Section 3.4.4.

A variety of tools, such as labels, texts, option buttons, command buttons, check boxes, combo boxes, and images, are provided in the forms to simplify the input and output for the user. These tools are enabled only when they are necessary for data input; otherwise, they are disabled (ineffective) to avoid confusing the user. The user interface displays help and useful details, like explanations about the system, flow charts, and guides. Users can input the required information by clicking to choose the offered options, which cover all of the probable required input data. The system responds immediately by analyzing the inputs in the inference mechanism to provide solutions.

\subsection{System verification and validation}

Verification and validation are the most important and difficult tasks involved in intelligent system development (Aguilar et al. 2008). Verification can be performed through testing activities to verify that the correct system is being built. In effective testing, each test should aim to detect a fault. Each stage and all components of the system should be tested (Qian et al. 2005). Testing is performed periodically during the system development process to guarantee that each activity in the system is performing the intended functions. ES-CCPRHP is evaluated by a number of test procedures, as explained in the following sections.

\subsubsection{Unit and integration testing}

Unit testing means testing the units one by one by separate testing activities (Aguilar et al. 2008). This testing was performed continually during all of the stages of development of ES-CCPRHP to verify that each unit in the system performs the intended function. The internal structure of the system is checked by the knowledge engineer by covering all possible combinations of constants, variables, relationships among them, and paths of the source code. Few mistakes were diagnosed during the testing process. These mistakes were corrected, while the system was still under construction and before transforming it into an executable version.

Integration testing will be performed by the knowledge engineer to verify that all units are running together in the approved manner (Aguilar et al. 2008; Ooshaksaraie et al. 2012). To run the system, the user will provide the system with the required input data, such as the type of area, description of the problem, its location, and the layer where the problem is detected. The system is provided with many commands that simplify the mission of the user regardless of his skills in highway pavement construction and computer use. The user can enter his input data by clicking the options presented by the system. The input data are processed in the system to identify suitable solutions, possible causes, preventive actions, and the effects of the problem if no actions are taken to control it. The interaction between the user and the ES-CCPRHP was tested by the knowledge engineer. Similar to unit testing, integration testing was performed periodically during construction of ES-CCPRHP to verify its capability to execute the intended functions.

\subsubsection{User satisfaction testing}

A questionnaire survey was designed to test users' satisfaction with ES-CCPRHP. Three groups of users were selected to participate in these surveys. The first group includes 5 computer specialists. The second group includes four experts in rigid highway pavement construction, who were not involved in the knowledge elicitation stage. The third group consists of 10 novice engineers. The backgrounds of the users mentioned above are listed in Table 4.

The system was used by the participants to evaluate the system depending on the questionnaire presented in Table 5. The result of evaluation reflects the satisfaction of the users through their high mean ratings (more than 3). Validation is performed to ensure that the system represents the knowledge of the experts accurately (Aguilar et al. 2008). The satisfaction of the users in the second group (domain experts) can be considered as evidence for the system's validation as these users are satisfied with the knowledge base content, its speed, help facilities, system results, and other components in the system, as listed in Table 5. Satisfaction of the users in all groups (computer professionals, experts and novice engineers) indicates that the user interface is friendly.

Questionnaire reliability was statistically tested by calculating Cronbach's alpha, which was 0.969 , indicating high reliability. The mean and standard deviation values of the evaluation results for each group of participants were calculated. The results were then statistically tested by one-way ANOVA at a 95\% confidence level (Table 5). The test shows no significant difference between the mean values of the groups for questions 1, 2, 3, 4, 5, 10, and 16 . However, a significant difference was found between the mean values of the groups for questions $6,7,8,9,11,12$, 13,14 , and 15 because the calculated $F$ value is higher than the tabulated $\mathrm{F}$ value (3.634). The test indicates that at least one group differs from another, but does not show which group pair or pairs cause the differences. Therefore, the least significant difference (LSD) test by Tukey's method was adopted to specify the pair or pairs from which the differences originate. Following this method, 
Table 4. Backgrounds of the users involved in system testing

\begin{tabular}{|c|c|c|c|c|}
\hline Group & User & Specialization & Degree & Years of experience \\
\hline \multirow{5}{*}{ Group 1} & 1 & Computer engineering specialist & Master & 10 \\
\hline & 2 & Information technology specialist & Master & 7 \\
\hline & 3 & Information technology specialist & Master & 6 \\
\hline & 4 & Software engineering specialist & Master & 6 \\
\hline & 5 & Computer science specialist & Master & 5 \\
\hline \multirow{4}{*}{ Group 2} & 1 & Domain expert & Master & 25 \\
\hline & 2 & Domain expert & Master & 25 \\
\hline & 3 & Domain expert & Master & 20 \\
\hline & 4 & Domain expert & Master & 20 \\
\hline \multirow{10}{*}{ Group 3} & 1 & Highway engineer & Bachelor & 2 \\
\hline & 2 & Highway engineer & Bachelor & 2 \\
\hline & 3 & Highway engineer & Bachelor & 2 \\
\hline & 4 & Highway engineer & Bachelor & 2 \\
\hline & 5 & Highway engineer & Bachelor & 2 \\
\hline & 6 & Highway engineer & Bachelor & 1 \\
\hline & 7 & Highway engineer & Bachelor & 1 \\
\hline & 8 & Highway engineer & Bachelor & 1 \\
\hline & 9 & Civil engineer & Bachelor & 0 \\
\hline & 10 & Civil engineer & Bachelor & 0 \\
\hline
\end{tabular}

Table 5. Result of ES-CCPRHP evaluation statistically tested by ANOVA

\begin{tabular}{|c|c|c|c|c|c|c|c|c|c|}
\hline \multirow[b]{2}{*}{ No. } & \multirow[b]{2}{*}{ Questions } & \multicolumn{2}{|c|}{ Group 1} & \multicolumn{2}{|c|}{ Group 2} & \multicolumn{2}{|c|}{ Group 3} & \multirow[b]{2}{*}{$F^{*}$} & \multirow[b]{2}{*}{$p$} \\
\hline & & Mean & SD & Mean & SD & Mean & $\mathrm{SD}$ & & \\
\hline Q1 & ES-CCPRHP is easy to use & 3.40 & 0.55 & 4.00 & 0.00 & 3.70 & 0.48 & 1.96 & 0.17 \\
\hline Q2 & ES-CCPRHP runs quickly & 5.00 & 0.00 & 5.00 & 0.00 & 5.00 & 0.00 & - & - \\
\hline Q3 & The user interface is user friendly & 4.00 & 0.00 & 4.00 & 0.82 & 4.20 & 0.79 & 0.20 & 0.82 \\
\hline Q4 & $\begin{array}{l}\text { Obtaining an explanation from ES- } \\
\text { CCPRHP is easy }\end{array}$ & 3.40 & 0.55 & 4.25 & 0.96 & 4.30 & 0.67 & 2.10 & 0.08 \\
\hline Q5 & The explanations are useful & 3.60 & 0.55 & 4.25 & 0.96 & 4.30 & 0.67 & 1.74 & 0.21 \\
\hline Q6 & Help facilities are effective & 3.40 & 0.55 & 4.25 & 0.96 & 4.40 & 0.52 & $4.29 * *$ & 0.03 \\
\hline Q7 & The questions are helpful & 3.40 & 0.55 & 4.50 & 0.58 & 4.50 & 0.53 & $7.513 * *$ & 0.005 \\
\hline Q8 & The questions are clear & 3.60 & 0.55 & 4.50 & 0.58 & 4.50 & 0.53 & $5.029 * *$ & 0.020 \\
\hline Q9 & The terms are clear & 3.60 & 0.55 & 4.50 & 0.58 & 3.80 & 0.42 & $4.181 * *$ & 0.035 \\
\hline Q10 & Presentation of results is clear & 3.60 & 0.55 & 4.25 & 0.50 & 4.10 & 0.57 & 1.884 & 0.184 \\
\hline Q11 & Presentation of results is complete & 3.60 & 0.55 & 4.50 & 0.58 & 4.40 & 0.52 & $4.398 * *$ & 0.030 \\
\hline Q12 & ES-CCPRHP is helpful to provide solutions & 3.60 & 0.55 & 4.00 & 0.00 & 4.60 & 0.52 & $7.812 * *$ & 0.004 \\
\hline Q13 & $\begin{array}{l}\text { ES-CCPRHP is helpful to specify the } \\
\text { causes of problems }\end{array}$ & 3.60 & 0.55 & 4.80 & 0.63 & 4.90 & 0.45 & $11.336 * *$ & 0.001 \\
\hline Q14 & $\begin{array}{l}\text { ES-CCPRHP is helpful to adopt preventive } \\
\text { actions }\end{array}$ & 3.60 & 0.55 & 4.80 & 0.63 & 4.90 & 0.45 & $11.336 * *$ & 0.001 \\
\hline Q15 & $\begin{array}{l}\text { ES-CCPRHP is helpful to specify effects of } \\
\text { problems }\end{array}$ & 3.60 & 0.55 & 4.80 & 0.63 & 4.90 & 0.45 & $11.336 * *$ & 0.001 \\
\hline Q16 & Generally, I am satisfied with ES-CCPRHP & 3.80 & 0.44 & 4.00 & 0.82 & 4.50 & 0.72 & 1.993 & 0.169 \\
\hline
\end{tabular}

*Confidence level $=95 \%, F$ table $=3.634$.

${ }^{* *} F_{\text {calculated }}>F_{\text {tabulated: }}$ A significant difference was found between the mean values in a group pair or more. 
Table 6. Least significant difference test (Tukey's method)

\begin{tabular}{|c|c|c|c|c|c|}
\hline \multirow[b]{2}{*}{$Q$} & \multirow[b]{2}{*}{$F$} & \multirow[b]{2}{*}{ LSD } & \multicolumn{3}{|c|}{ Difference between mean values } \\
\hline & & & $\mathrm{G} 1-\mathrm{G} 2$ & G1-G3 & G2-G3 \\
\hline 6 & $4.290 *$ & 0.754 & $0.85^{*}$ & $1^{*}$ & 0.15 \\
\hline 7 & $7.513^{*}$ & 0.6493 & $1.1^{*}$ & $1.1^{*}$ & 0.0 \\
\hline 8 & $5.029^{*}$ & 0.6493 & $0.9^{*}$ & $0.9^{*}$ & 0.0 \\
\hline 9 & $4.181 *$ & 0.5814 & $0.9 *$ & $0.2^{*}$ & 0.7 \\
\hline 11 & $4.398^{*}$ & 0.6428 & $0.9^{*}$ & $0.8^{*}$ & 0.1 \\
\hline 12 & $7.812 *$ & 0.5688 & $0.4^{*}$ & $1.0^{*}$ & $0.6^{*}$ \\
\hline 13 & $11.336^{*}$ & 0.6125 & $1.2 *$ & $1.3^{*}$ & 0.1 \\
\hline 14 & $11.336^{*}$ & 0.6125 & $1.2^{*}$ & $1.3^{*}$ & 0.1 \\
\hline 15 & $11.336^{*}$ & 0.6125 & $1.2 *$ & $1.3^{*}$ & 0.1 \\
\hline
\end{tabular}

*There is significant difference between the mean values in the group pair.

we calculated the difference between each two mean values and compared it with LSD. Table 6 abstracts the result of the comparison. For all the questions, the differences between the mean values of groups 1 and 2 and between groups 1 and 3 were higher than the LSD, indicating significant differences between the mean values of group 1 and those of groups 2 and 3. Conversely, no significant differences were found between the mean values of groups 2 and 3, except for question 12. With respect to questions 6-9 and 11-15 (those related to the evaluation of the knowledge included in the system), the mean values in the second group (domain experts) were very high. This result reflects the validity of the knowledge. The third group (novice highway engineers) also exhibited high mean values, because they have a reasonable background on the domain of the study. The first group had mean values higher than 3 but with significant difference from groups 2 and 3 because this group was not familiar with pavement construction.

\subsubsection{Behavior comparison between ES-CCPRHP and experts}

Another measure for system validation involves presenting the inputs and outputs of the system to the second set of experts. The results given by the system are compared to the experts' opinions. The system was found to be compatible with their opinions regarding diagnosis, reasoning, conclusions and decisions. Moreover, the experts approved the results presented by the system that related to the causes of the problems, the preventive actions, and their possible effects. The results of validation show that the system provides output that matches the opinions of the second set of experts, as well as those of the first set of experts, who were involved in the knowledge elicitation stage, on whose knowledge the system was based. The overall compatibility between the system and the first set of experts amounts to $97 \%$ as the knowledge is already documented based on their expertise. The overall compatibility between the system and the second set of experts amounts to $86 \%$. The variance between the system and the expert recommendation can be justified by the additional information provided by the system according to literature. The system is thus established to be valid and can be used with confidence.

Table 7 presents the factors affecting the evaluation of plastic concrete loads supplied to the construction site as an example of the comparison process.

\subsubsection{Testing by case study}

This test was done to validate the system in a real environment. In this step, a construction site was selected. At this site, the new pavement was evaluated by ESCCPRHP, and the recommendations obtained were compared with the recommendations reported by the Highway Division in the Department of General Works. The results obtained from the system were in line with the results of the reports. In addition, the results given by the system were checked and approved by the second set of domain experts.

In the selected section, 11 portions were reported as problematic because of deficiencies in structural properties. For example, thickness and concrete compressive strength were less than those required by the design documents. Of these portions, we selected a final set of four (shown in Table 8) as the illustrative examples. Input data were obtained from the reports and entered into the system to evaluate the specified portions. The design data were the same for all the portions, whereas the data obtained from the site differed for each portion.

After running the system, the evaluation screen is displayed by selecting the option "structural property deficiency problems" from the main screen. The evaluation screen is shown in Figure 4.

The initial requested input data are:

$D_{\text {req }}$ : pavement slab depth required by the project documents [design] (mm);

$D_{f}$ : constructed pavement slab depth measured in the field $(\mathrm{mm})$;

$C S_{\text {req }}$ : concrete compressive strength required by the project documents [design] (MPa);

$C S_{f}$ : concrete compressive strength measured by testing the cores drilled from the field (MPa).

The inference engine of the system will manipulate these inputs and search the knowledge base for the matching rule as shown below:

IF $D_{r e q}-D_{f} \leq 13 \mathrm{~mm}$ and $C S_{r e q} \leq C S_{f}$, THEN Accept the portion

IF $D_{r e q}-D_{f} \leq 13 \mathrm{~mm}$ and $C S_{r e q} \geq C S_{f}$, THEN Apply Redesign Procedure

IF $D_{\text {req }}-D_{f} \geq 13 \mathrm{~mm}$ and $C S_{\text {req }} \leq C S_{f}$, THEN Apply Redesign Procedure

IF $D_{\text {req }}-D_{f} \geq 13 \mathrm{~mm}$ and $C S_{r e q} \geq C S_{f}$, THEN Reject the portion.

When the system conclusion is "accept the portion", the system will display an output screen to notify the user that the portion can be accepted if there are no other problems; otherwise, the other properties will be evaluated. In addition, the system offers to calculate the value of price deduction, if required. 
Table 7. Example of comparison between ES-CCPRHP and expert reasoning

Considered parameters in evaluation of concrete properties

\begin{tabular}{|l|l|l|l|l|l|l|l|l}
\hline \multicolumn{4}{|c|}{ First set of experts } & & \multicolumn{3}{|c}{ Second set of experts } \\
\cline { 1 - 1 } & 2 & 3 & 4 & ES-CCPRHP & 1 & 2 & 3 & 4 \\
\hline
\end{tabular}

Overall concrete appearance

\begin{tabular}{|c|c|c|c|c|c|c|c|c|c|}
\hline Homogenous/not homogenous & $\checkmark$ & $\checkmark$ & & & $\checkmark$ & & & & $\checkmark$ \\
\hline Coarse (harsh)/fine/regular & $\checkmark$ & $\checkmark$ & $\checkmark$ & & $\checkmark$ & & & & $\checkmark$ \\
\hline Stiff/high liquidity & $\checkmark$ & $\checkmark$ & & $\checkmark$ & $\checkmark$ & & $\checkmark$ & $\checkmark$ & \\
\hline Rich with cement/poor with cement & $\checkmark$ & & $\checkmark$ & & $\checkmark$ & & $\checkmark$ & & \\
\hline Segregated/not segregated & $\checkmark$ & $\checkmark$ & $\checkmark$ & $\checkmark$ & $\checkmark$ & $\checkmark$ & $\checkmark$ & $\checkmark$ & $\checkmark$ \\
\hline Contaminated/not contaminated & $\checkmark$ & $\checkmark$ & & & $\checkmark$ & & & & \\
\hline
\end{tabular}

Concrete temperature

\begin{tabular}{l|c|c|c|c|c|c|c|c|c}
\hline Maximum & $\checkmark$ & $\checkmark$ & $\checkmark$ & $\checkmark$ & $\checkmark$ & $\checkmark$ & $\checkmark$ & $\checkmark$ & $\checkmark$ \\
\hline Minimum & $\checkmark$ & $\checkmark$ & $\checkmark$ & & $\checkmark$ & $\checkmark$ & $\checkmark$ & & $\checkmark$ \\
\hline
\end{tabular}

Weather conditions

\begin{tabular}{|c|c|c|c|c|c|c|c|c|c|}
\hline Ambient temperature & $\checkmark$ & $\checkmark$ & $\checkmark$ & $\checkmark$ & $\checkmark$ & $\checkmark$ & $\checkmark$ & $\checkmark$ & $\checkmark$ \\
\hline Rainy/windy/dusty/clear & $\checkmark$ & $\checkmark$ & $\checkmark$ & $\checkmark$ & $\checkmark$ & $\checkmark$ & $\checkmark$ & $\checkmark$ & $\checkmark$ \\
\hline \multicolumn{10}{|l|}{ Economical factors } \\
\hline money saving/money wastage & $\checkmark$ & $\checkmark$ & $\checkmark$ & $\checkmark$ & $\checkmark$ & $\checkmark$ & $\checkmark$ & $\checkmark$ & $\checkmark$ \\
\hline resources saving/resources wastage & $\checkmark$ & $\checkmark$ & & $\checkmark$ & $\checkmark$ & $\checkmark$ & $\checkmark$ & & \\
\hline \multicolumn{10}{|l|}{ Diagnosing criteria } \\
\hline Records reviewing & $\checkmark$ & $\checkmark$ & $\checkmark$ & $\checkmark$ & $\checkmark$ & $\checkmark$ & $\checkmark$ & $\checkmark$ & $\checkmark$ \\
\hline Testing and measurement & $\checkmark$ & $\checkmark$ & $\checkmark$ & $\checkmark$ & $\checkmark$ & $\checkmark$ & $\checkmark$ & $\checkmark$ & $\checkmark$ \\
\hline visual check & $\checkmark$ & $\checkmark$ & $\checkmark$ & $\checkmark$ & $\checkmark$ & $\checkmark$ & $\checkmark$ & $\checkmark$ & $\checkmark$ \\
\hline GIS & & & & & $\checkmark$ & & & & \\
\hline
\end{tabular}

Conclusion

\begin{tabular}{|c|c|c|c|c|c|c|c|c|c|}
\hline Effects on pavement: no effects/minor effects/severe effects & $\checkmark$ & $\checkmark$ & $\checkmark$ & $\checkmark$ & $\checkmark$ & $\checkmark$ & $\checkmark$ & $\checkmark$ & $\checkmark$ \\
\hline $\begin{array}{l}\text { Solutions: accept/report/take additional samples/do more tests/ } \\
\text { rectify/reject }\end{array}$ & $\checkmark$ & $\checkmark$ & $\checkmark$ & $\checkmark$ & $\checkmark$ & $\checkmark$ & $\checkmark$ & $\checkmark$ & $\checkmark$ \\
\hline Causes & $\checkmark$ & $\checkmark$ & $\checkmark$ & $\checkmark$ & $\checkmark$ & $\checkmark$ & $\checkmark$ & 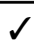 & $\checkmark$ \\
\hline preventive actions & $\checkmark$ & $\checkmark$ & $\checkmark$ & $\checkmark$ & $\checkmark$ & $\checkmark$ & $\checkmark$ & $\checkmark$ & $\checkmark$ \\
\hline
\end{tabular}

According to the second and third rules, the inference engine will run the redesign subroutine to calculate the minimum thickness that is structurally accepted on the basis of the AASHTO procedure. The calculation is performed according to the following equation (AASHTO 1993):

$$
\begin{aligned}
& \log _{10}\left(W_{18}\right)=Z_{R} \times S_{o}+7.35 \times \log _{10}(D+1)- \\
& 0.06+\frac{\log _{10}\left(\frac{\Delta P S I}{4.5-1.5}\right)}{1+\frac{1.624 \times 10^{7}}{(D+1)^{8.46}}+\left(4.22-0.32 p_{t}\right) \times} \\
& \log _{10}\left[\frac{\left(S_{c}^{\prime}\right)\left(C_{d}\right)\left(D^{0.75}-1.132\right)}{215.63(J)\left[D^{0.75}-\frac{18.42}{\left(\frac{E_{c}}{k}\right)}\right]}\right],
\end{aligned}
$$

where: $D$ - pavement slab depth calculated depending on field measures; $W_{18}$ - predicted number of $80 \mathrm{KN}(18,000 \mathrm{lb})$ equivalent single axle loads (ESALs); $Z_{R}-$ standard normal deviation; $S_{o}$ - combined standard error of traffic prediction and performance prediction; $C_{d}$ - drainage coefficient; $J-$ load transfer coefficient; $k$-modulus of subgrade reaction; $\triangle P S I$ - difference between the initial design serviceability index and the design terminal serviceability index $=p_{o}-p_{t}$, where $p_{t}$ is the terminal serviceability index and $p_{o}$ denotes the initial design serviceability index; $E_{c}-$ concrete elastic modulus $=57,000 \sqrt{C S_{f}} ; S_{c}^{\prime}$ - concrete modulus of rupture $=7.5 \sqrt{C S_{f}}$.

Redesign procedure:

1) Convert the units of $C S_{f}$ from $\mathrm{MPa}$ to psi;

2) Calculate $E_{c}$ and $S_{c}^{\prime}$;

3) Calculate $D$;

4) Convert the unit of $D$ from inch to $\mathrm{mm}$;

5) Compare:

IF $D-D_{f} \leq 13 \mathrm{~mm}$, THEN Accept the portion. IF $D-D_{f} \geq 13 \mathrm{~mm}$, THEN Reject the portion. 
Table 8. Evaluation of structural properties in four portions of the selected section in the case study

\begin{tabular}{|c|c|c|c|c|c|c|c|c|c|}
\hline \multicolumn{10}{|c|}{$\begin{array}{c}\text { Design data: } W_{18}=6000000 ; D_{\text {req }}=260 \mathrm{~mm} ; C S_{\text {req }}=35 \mathrm{MPa} ; J=3.2 ; C_{d}=1 ; p_{\mathrm{i}}=4.5, p_{\mathrm{t}}=3 ; \Delta P S I=1.5 ; k=54 \mathrm{MPa} / \mathrm{m} ; R=80 \% ; \\
S_{o}=0.4 ; Z_{R}=-0.841\end{array}$} \\
\hline \multirow[b]{3}{*}{$N$} & \multicolumn{2}{|c|}{ Input } & \multirow[b]{3}{*}{ Reasoning in inference engine } & \multicolumn{6}{|c|}{ Output } \\
\hline & \multirow{2}{*}{$D_{r e q}(\mathrm{~mm})$} & \multirow{2}{*}{$D_{f}(\mathrm{MPa})$} & & \multirow[b]{2}{*}{ ES-CCPRHP } & \multirow[b]{2}{*}{ Report } & \multicolumn{4}{|c|}{ Experts } \\
\hline & & & & & & 1 & 2 & 3 & 4 \\
\hline 1 & 262 & 36 & $\begin{array}{l}\left(D_{r e q}=260\right)-\left(D_{f}=262\right)=-2<13 \text { and }\left(C S_{r e q}=35\right)< \\
\left(C S_{f}=36\right) \text { THEN Accept the portion }\end{array}$ & Accept & Accept & $\checkmark$ & $\checkmark$ & $\checkmark$ & $\checkmark$ \\
\hline 2 & 255 & 30 & $\begin{array}{l}\left(D_{r e q}=260\right)-\left(D_{f}=255\right)=5<13 \text { and }\left(C S_{f}=35\right)> \\
\left(C S_{c}=30\right) \text { THEN Apply Redesign Procedure: } C S_{f}=4350 \\
\text { psi, } E_{\mathrm{c}}=3760000, S_{\mathrm{c}}=495, D=10.4 \mathrm{in}=264 \mathrm{~mm}(D= \\
264)-\left(D_{f}=255\right)=9<13 \mathrm{~mm} \text { THEN Accept the portion }\end{array}$ & Accept & Accept & $\checkmark$ & $\checkmark$ & $\checkmark$ & $\checkmark$ \\
\hline 3 & 249 & 27 & $\begin{array}{l}\left(D_{\text {req }}=260\right)-\left(D_{f}=249\right)=11<13 \text { and }\left(C S_{f}=35\right)> \\
\left(C S_{c}=27\right) \text { THEN Apply Redesign Procedure: } C S_{f}=3900, \\
E_{c}=3560000, S_{\mathrm{c}}=468, D_{f}=10.7 \mathrm{in}=272 \mathrm{~mm}(D=272)- \\
\left(D_{f}=249\right)=23>13 \mathrm{~mm} \text { THEN Reject the portion }\end{array}$ & Reject & Reject & $\checkmark$ & $\checkmark$ & $\checkmark$ & $\checkmark$ \\
\hline 4 & 245 & 32 & $\begin{array}{l}\left(D_{r e q}=260\right)-\left(D_{f}=245\right)=15>13 \text { and }\left(C S_{r e q}=35\right)> \\
\left(C S_{f}=32\right) \text { THEN Reject the portion }\end{array}$ & Reject & Reject & $\checkmark$ & $\checkmark$ & $\checkmark$ & $\checkmark$ \\
\hline
\end{tabular}

Table 8 abstracts input, inference, and output for four portions in this case study. Figures 4 and 5 illustrate the input and output screens, respectively.

\subsubsection{System updating and maintenance}

The system will be updated when new construction technologies, such as new materials, new concrete modifiers, new equipment, or new techniques, are applied in the rigid highway pavement industry. The system will also be updated when new design approaches are developed. Moreover, the creativity of humans is boundless; therefore, the system will be updated when new human expertise is developed. The operation of the system for several days can cause problems; if so, the system can be restarted to solve the problem.

\section{Conclusion}

Developing an expert system from scratch was the challenge of this study. The evaluation and development stages of ES-CCPRHP are described in detail in the domain of rigid highway pavement construction. The developed system will be helpful for highway engineers to overcome domain problems to detect problems and make decisions for solving problems quickly. The need

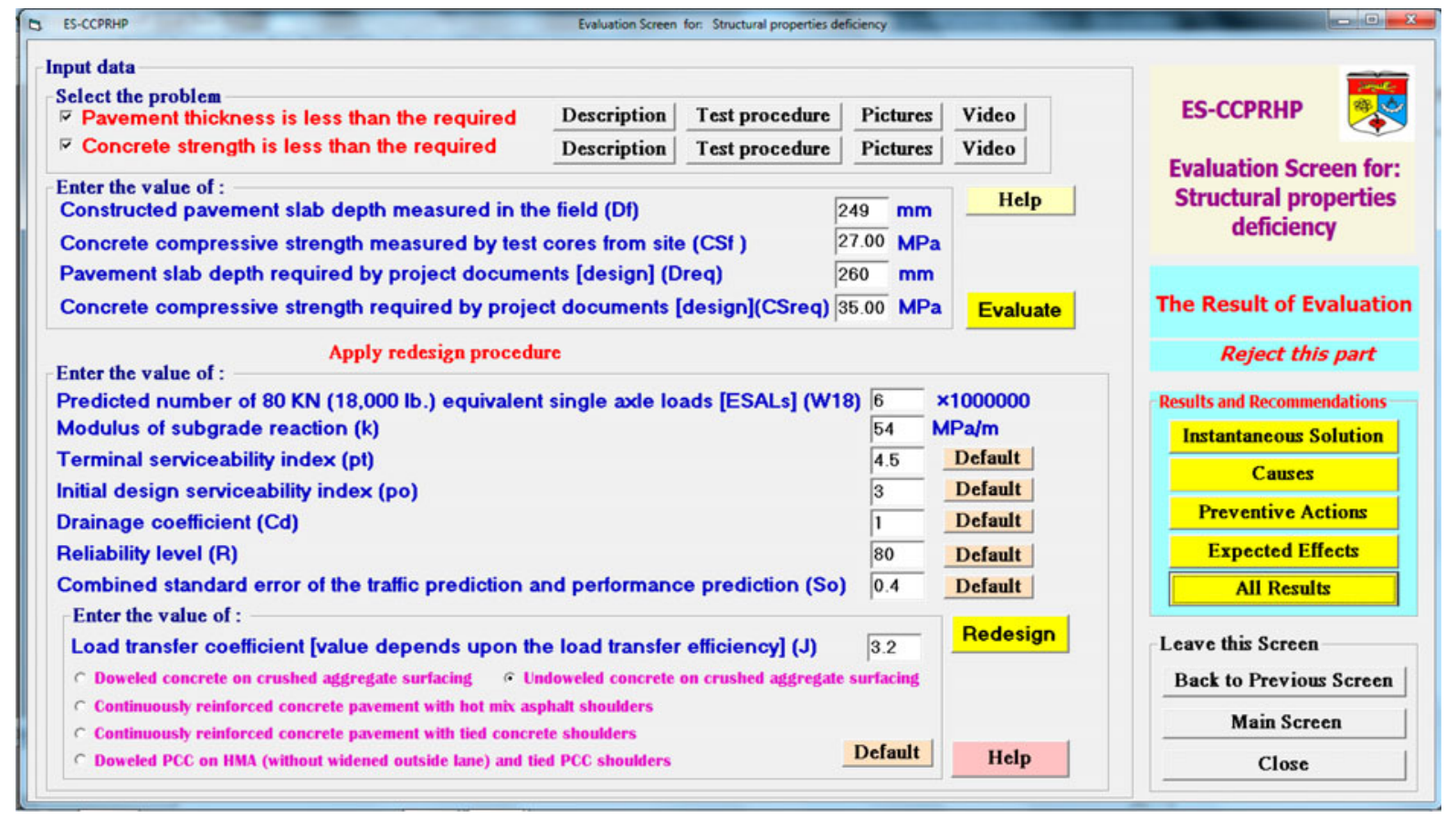

Fig. 4. ES-CCPRHP evaluation screen for structural property deficiencies 


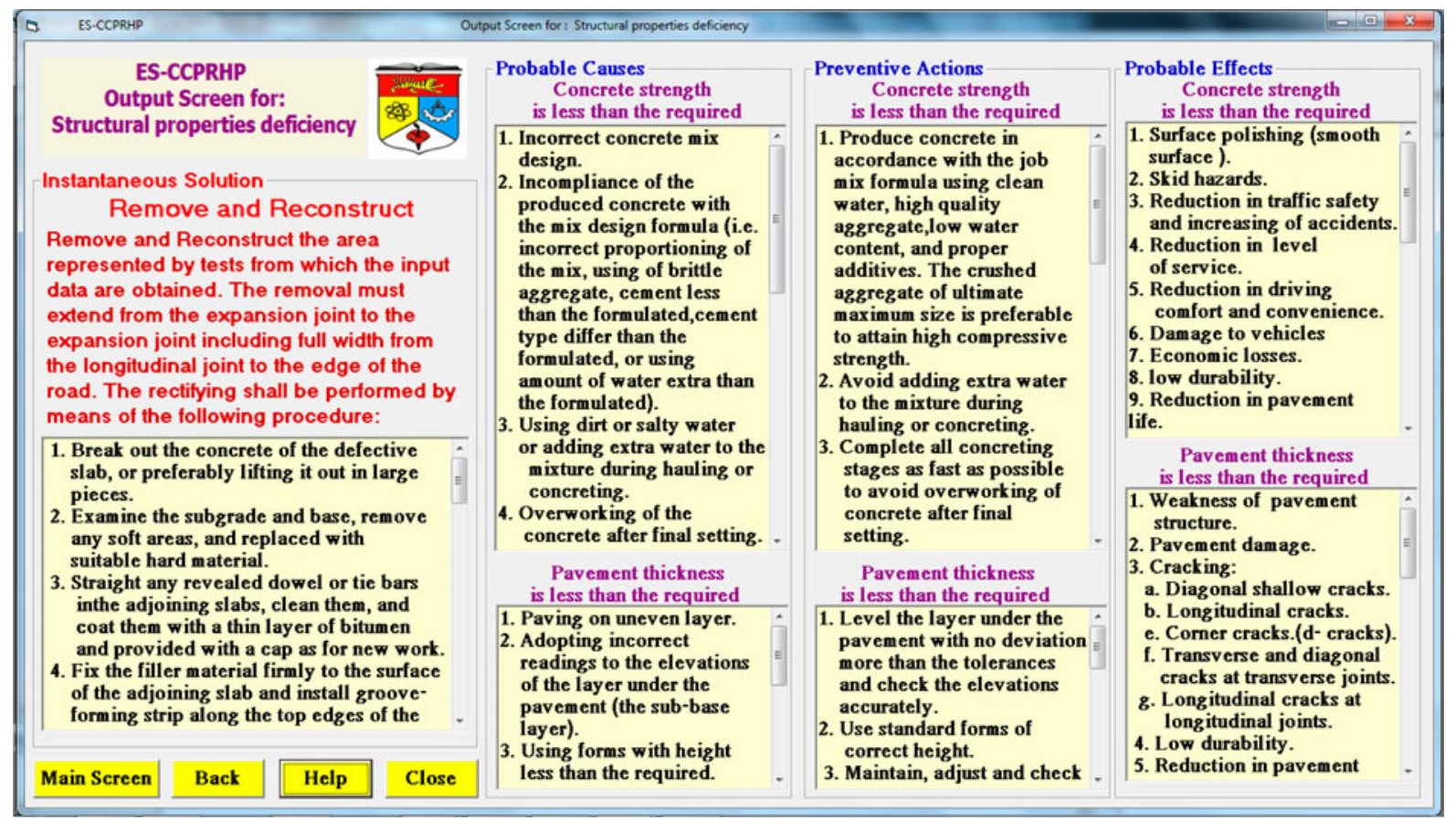

Fig. 5. ES-CCPRHP output screen for structural property deficiencies

for the system was validated by a questionnaire survey submitted to 30 highway engineers before the system development began. The knowledge base of the system is based primarily on human expertise and secondarily on a literature review. The knowledge base includes the problems encountered in the domain, their causes, preventive actions, instantaneous solutions, and their effects in a classified form. A database of relevant knowledge is represented in the form of rules and coded in this software coded in Microsoft Visual Basic environment and supported by GIS, which is compatible with Visual Basic. The system is verified and validated by extensive testing. Moreover the system has a flexible and user friendly interface. The system has been verified and validated and can be used confidently by end users. In addition, it can be used as a database to archive the problems encountered in the domain and to share highway engineers' experiences and transfer expertise to successive generations of engineers. Using this system as a foundation, other highway construction expert system can be developed. Any knowledgeable engineer or any competent user of Visual Basic can update this system under supervision by a highway engineer and make it more resourceful for new engineers.

The system is unsuitable for problems that occur in embankment, subgrade, subbase, and base construction, but it considers their effects on the construction of concrete pavements. The system is also inapplicable to prestressed concrete, pervious concrete, roller-compacted concrete, self-consolidating concrete and asphaltic shoulders. The system uses the AASHTO procedure in the redesign process and does not include other procedures. The system works in Microsoft Windows 2000 or higher and requires a memory space of $500 \mathrm{MB}$.

\section{References}

AASHTO. 2000. Guide for design of pavements structures. Washington D.C.: American Association of State Highways and Transportation Officials.

ACI Committee 116R-00. 2000. Cement and concrete terminology. Detroit: American Concrete Institute International.

ACI Committee 304R-00. 2000. Guide for measuring, mixing, transporting, and placing concrete. Detroit: American Concrete Institute International.

ACI Committee 305.1-06. 2007. Specification for hot weather concreting. Detroit: American Concrete Institute.

ACI Committee 306.1-90. 2002. Standard specification for cold weather concreting. Detroit: American Concrete Institute.

Aguilar, R. M.; Muñoz, V.; Noda, M.; Bruno, A.; Moreno, L. 2008. Verification and validation of an intelligent tutorial system, Expert Systems with Applications 35(3): 77-85. http://dx.doi.org/10.1016/j.eswa.2007.07.024

Ahmadi, F. F.; Ebadi, H. 2010. Design and implementation of an expert interface system for integration of photogrammetric and Geographic Information Systems for intelligent preparation and structuring of spatial data, Expert Systems with Applications 37(12): 6-13.

Alani, I. A. R.; Basri, N. E. A.; Abdullah, R. A.; Ismail, A. 2009. Artificial intelligence expert system for minimizing solid waste during highway construction activities, in Proc. of the International Multiconference of Engineers and Computer Scientists, March 18-20, 2009, Hong Kong, 54-57.

Castellanos, V.; Albiter, A.; Hernández, P.; Barrera, G. 2011. Failure analysis expert system for onshore pipelines. Part I: structured database and knowledge acquisition, Expert Systems with Applications 38(9): 85-90. http://dx.doi.org/10.1016/j.eswa.2011.02.153

Cebi, S.; Celik, M.; Kahraman, C.; Er, D. I. 2009. An expert system towards solving ship auxiliary machinery troubleshooting: SHIPAMTSOLVER, Expert Systems with Applications 36(3, Part 2): 19-27.

http://dx.doi.org/10.1016/j.eswa.2008.09.060 
Chou, J. S.; Tseng, H. C. 2011. Establishing expert system for prediction based on the project-oriented data warehouse, Expert Systems with Applications 38(1): 40-51. http://dx.doi.org/10.1016/j.eswa.2010.07.015

Chu, Y.-S.; Tseng, S.-S.; Tsai, Y.-J.; Luo, R.-J. 2009. An intelligent questionnaire analysis expert system, Expert Systems with Applications 36(2, Part 2): 699-710. http://dx.doi.org/10.1016/j.eswa.2008.01.076

Demircan, S.; Aydin, M.; Durduran, S. S. 2011. Finding optimum route of electrical energy transmission line using multi-criteria with Q-learning, Expert Systems with Applications 38(4): 77-82. http://dx.doi.org/10.1016/j.eswa.2010.08.135

Deprizon, S.; Ismail, A.; Atiq, R. 2009. Development of knowledge-based expert system for flexible pavement design, Journal of Applied Sciences 9(13): 72-80.

Durduran, S. S. 2010. A decision making system to automatic recognize of traffic accidents on the basis of a GIS platform, Expert Systems with Applications 37(12): 29-36. http://dx.doi.org/10.1016/j.eswa.2010.04.068

Göb, R.; McCollin, C.; Ramalhoto, M. F. 2007. Ordinal methodology in the analysis of Likert scales, Quality and Quantity 41(5): 1-26.

Goh, A. T. C. 1993. Advisory expert system for flexible pavement design, Artificial Intelligence in Engineering 8(1): 47-56. http://dx.doi.org/10.1016/0954-1810(93)90030-J

Hozayen, H.; Haas, R. 1992. Pavement materials selection and evaluation utilizing knowledge-based expert systems technology. The Association of Asphalt Paving Technologists, Charleston, South Carolina, USA, 241-271.

Ismail, N.; Ismail, A.; Atiq, R. 2009a. An overview of expert systems in pavement management, European Journal of Scientific Research 30(1): 99-111.

Ismail, N.; Ismail, A.; Rahmat, R. A. O. K. 2009b. Development of expert system for airport pavement maintenance and rehabilitation, European Journal of Scientific Research 35(1): 21-29.

Kaur, D.; Tekkedil, D. 2000. Fuzzy expert system for asphalt pavement performance prediction, in Proc. of the IEEE Conference on Intelligent Transportation Systems, ITSC, Dearborn (MI), USA October 1-3, 2000, 28-33.

Khedr, S.; Mikhail, M. 1996. Design of flexible pavements and overlay using an expert system, Transportation Research Record: Journal of the Transportation Research Board 1543: 20-28. http://dx.doi.org/10.3141/1543-03

Kuprenas, J. A.; Salazar, R.; Posada, R. 1995. Expert system for the identification of causes of failure of asphalt concrete pavement, in Proc. of Computing in Civil Engineering, Atlanta, Georgia, United States, 582-588.

Lan, C.; Chang, C.-Y.; Huang, P.-J.; Liu, C.-H. 1993. PDS: an expert system for distress diagnosis of flexible pavements in Taiwan, in Proc. of Computing in Civil and Building Engineering, Anaheim, California, United States, 869-876.

Lee, J.; Suh, E.; Hong, J. 2010. A maturity model based CoP evaluation framework: a case study of strategic CoPs in a Korean company, Expert Systems with Applications 37(3): 2670-2681. http://dx.doi.org/10.1016/j.eswa.2009.08.011

Ma, Z.; Shao, C.; Ma, S.; Ye, Z. 2011. Constructing road safety performance indicators using Fuzzy Delphi method and Grey Delphi method, Expert Systems with Applications 38(3): 1509-1514.

http://dx.doi.org/10.1016/j.eswa.2010.07.062

Miller, S.; Huerne, H.; Dorée, A. 2007. The asphalt paving process: plans for action research, in Atkin, B.; Borgbrant, J. (Eds.). Proc. of the Fourth Nordic Conference on Construction
Economics and Organisation Development Processes in Construction Management. Luleå, Sweden: Department of Civil and Environmental Engineering, Luleå University of Technology, 37-46.

Mohd. Zain, F. M.; Islam, M. N.; Basri, I. H. 2005. An expert system for mix design of high performance concrete, Advances in Engineering Software 36(5): 325-337. http://dx.doi.org/10.1016/j.advengsoft.2004.10.008

Mohsen, J. P.; Crowder, T. R. 1991. Development of a pavement design expert system, in Proc. of Electronic Computation, Indianapolis, Indiana, United States, 1-7.

Mulungye, R. M.; Owende, P. M. O.; Mellon, K. 2007. Finite element modelling of flexible pavements on soft soil subgrades, Materials and Design 28: 739-756. http://dx.doi.org/10.1016/j.matdes.2005.12.006

Negnevitsky, M. 2005. Artificial intelligence: a guide to intelligent systems. Harlow: Addison-Wesley. 415 p.

Niaraki, A. S.; Kim, K. 2009. Ontology based personalized route planning system using a multi-criteria decision making approach, Expert Systems with Applications 36: 2250-2259. http://dx.doi.org/10.1016/j.eswa.2007.12.053

O'Flaherty, C. A. 1988. Highway engineering. Britain: British library cataloguing in publication data. $684 \mathrm{p}$.

Oglesby, H.; Claskson, R.; Hicks, G. 1982. Highway engineering. Singapore: John Wiley and Sons Ltd. 858 p.

Ooshaksaraie, L.; Basri, N. E. A.; Bakar, A. A.; Maulud, K. N. A. 2012. RP3CA: an expert system applied in storm water management plan for construction sites in Malaysia, Expert Systems with Applications 39(3): 3692-3701. http://dx.doi.org/10.1016/j.eswa.2011.09.064

Osuagwu, C. C.; Okafor, E. C. 2010. Framework for eliciting knowledge for a medical laboratory diagnostic expert system, Expert Systems with Applications 37(7): 5009-5016. http://dx.doi.org/10.1016/j.eswa.2009.12.012

Park, J.-H.; Song, J.-H.; Lee, T.; Lee, K.-S. 2010. Implementation of expert system on estimation of fatigue properties from monotonic mechanical properties including hardness, Procedia Engineering 2: 1263-1272. http://dx.doi.org/10.1016/j.proeng.2010.03.137

Persson, M.; Landin, A. 2007. The transfer of experience in a construction company, in Proc. of the Fourth Nordic Conference on Construction Economics and Organisation Development Processes in Construction Management, Atkin, B.; Borgbrant, J. (Eds.). Luleå, Sweden: Luleå University of Technology, Department of Civil and Environmental Engineering, 93-104.

Přibyl, O. 2010. FESOLE-fuzzy expert system for determining the optimal level of enforcement, IET Intelligent Transport Systems 4(1): 76-81.

http://dx.doi.org/10.1049/iet-its.2009.0011

Qian, Y.; Xu, L.; Li, X.; Lin, L.; Kraslawski, A. 2008. LUBRES: an expert system development and implementation for realtime fault diagnosis of a lubricating oil refining process, Expert Systems with Applications 35(3): 1252-1266. http://dx.doi.org/10.1016/j.eswa.2007.07.061

Qian, Y.; Zheng, M.; Li, X.; Lin, L. 2005. Implementation of knowledge maintenance modules in an expert system for fault diagnosis of chemical process operation, Expert Systems with Applications 28(2): 249-257. http://dx.doi.org/10.1016/j.eswa.2004.10.005

Raza, F. N. 2009. Artificial intelligence techniques in software engineering (AITSE), in Proc. of the International MultiConference of Engineers and Computer Scientists, March 18-20, 2009, Hong Kong, 1086-1088.

Rezaei, J.; Ortt, R.; Scholten, V. 2011. Measuring entrepreneurship: expert-based vs. data-based methodologies, Expert 
Systems with Applications 39: 4063-4074.

http://dx.doi.org/10.1016/j.eswa.2011.09.091

Ruiz-Mezcua, B.; Garcia-Crespo, A.; Lopez-Cuadrado, J. L.; Gonzalez-Carrasco, I. 2011. An expert system development tool for non AI experts, Expert Systems with Applications 38(1): 597-609.

http://dx.doi.org/10.1016/j.eswa.2010.07.009

Sadeghi-Niaraki, A.; Varshosaz, M.; Kim, K.; Jung, J. J. 2011. Real world representation of a road network for route planning in GIS, Expert Systems with Applications 38(10): 1999-2008. http://dx.doi.org/10.1016/j.eswa.2010.12.123

Santos, G.; Behrendt, H.; Maconi, L.; Shirvani, T.; Teytelboym, A. 2010. Part I: Externalities and economic policies in road transport, Research in Transportation Economics 28(1): 2-45. http://dx.doi.org/10.1016/j.retrec.2010.03.002

Sikder, I. U. 2009. Knowledge-based spatial decision support systems: an assessment of environmental adaptability of crops, Expert Systems with Applications 36(3, Part 1): 5341-5347. http://dx.doi.org/10.1016/j.eswa.2008.06.128

Špundak, M.; Bogunović, N.; Fertalj, K. 2010. Web shop user error detection based on rule based expert system, in Proc. of the 33rd International Convention, May 24-28, 2010, Opatija, Croatia, 603-608.
Syamsunur, D.; Ismail, A.; Atiq, R.; Karim, O. A. 2011. Knowledge-based expert system for route selection of road alignment, Australian Journal of Basic and Applied Sciences 5(5): 208-213.

Tan, K.; Baxter, G.; Newell, S.; Smye, S.; Dear, P.; Brownlee, K.; Darling, J. 2010. Knowledge elicitation for validation of a neonatal ventilation expert system utilising modified Delphi and focus group techniques, International Journal of Human Computer Studies 68(6): 344-354. http://dx.doi.org/10.1016/j.ijhcs.2009.08.003

Teh, K. T.; Muniandy, R.; Hassan, A.; Hassim, S.; Omar, H. 2005. The development of road construction material selection system (RC-MSS), Journal of the Eastern Asia Society for Transportation Studies 6: 16.

Tsao, S.; Kehtarnavaz, N.; Chan, P.; Lytton, R. 1994. Image-based expert-system approach to distress detection on CRC pavement, Journal of Transportation Engineering 120(1): 52-64. http://dx.doi.org/10.1061/(ASCE)0733-947X(1994)120:1(52)

Wei, H.; Xu, Q. X.; Tang, X. S. 2011. A knowledge-based problem solving method in GIS application, KnowledgeBased Systems 24(4): 542-53. http://dx.doi.org/10.1016/j.knosys.2011.01.007

Ahmed Mancy MOSA. A PhD candidate at the Department of Civil and Structural Engineering, Kebangsaan University, Malaysia. He was a lecturer at the Department of Highway and Transportation, University of Mustansiryah, Baghdad, Iraq. He received his Master's degree in 2000 from University of Mustansiryah, Baghdad, Iraq. His main research interest is highway and transportation engineering, particularly on the applications of expert system in pavement engineering.

Mohd Raihan TAHA. A Professor and a Head at the Department of Civil and Structural Engineering, Kebangsaan University, Malaysia. He is a Graduate member of The Institution of Engineers, Malaysia. He was the recipient of various awards. He received his PhD in 1996 from Louisiana State University, Baton Rouge, USA. His main research interest is geotechnical and geo-environmental engineering, particularly on the applications of nano-materials in soil remediation and improvement, numerical modeling and constitutive relations.

Amiruddin ISMAIL. A Professor at the Department of Civil and Structural Engineering, Kebangsaan University, Malaysia. He is a Head of Sustainable Urban Transport Research Center (SUTRA), Faculty of Engineering and Built Environment, Kebangsaan University, Malaysia. He is a Professional Engineer, Board of Engineers, Malaysia, 1987. He was the recipient of a number of various awards He received his PhD in 2002 from Kebangsaan University, Malaysia, Bangi. His main research interest is highway and transportation engineering, particularly on the applications of expert system in pavement engineering, traffic engineering, public transport, and accidents' control.

Riza Atiq O. K. RAHMAT. A Professor at the Department of Civil and Structural Engineering, University Kebangsaan, Malaysia. He is a Head of Center of Academic advancement, University Kebangsaan, Malaysia. He is a Professional Engineer at the Board of Engineers, Malaysia, 1987. He has received a number of various awards. He received his $\mathrm{PhD}$ in 2002 from Universiti Kebangsaan Malaysia, Bangi, Malaysia. His main research interest is highway and transportation engineering, particularly on the applications of expert system in pavement engineering, traffic engineering, public transport, and accidents' control. 